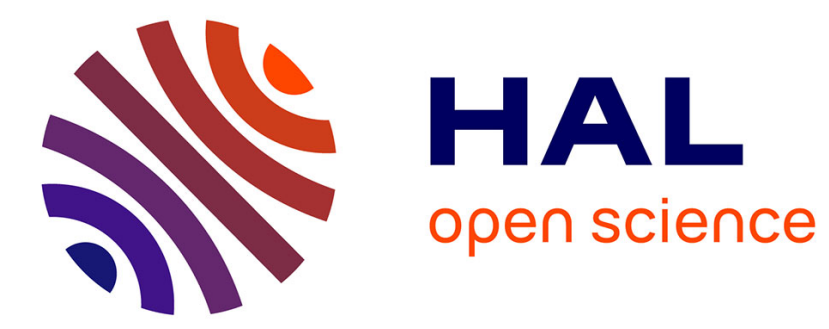

\title{
Influence of temperature on the compaction of an organic powder and the mechanical strength of tablets.
}

Emilie Rouèche, Eric Serris, Gérard Thomas, Laurent Périer-Camby

\section{To cite this version:}

Emilie Rouèche, Eric Serris, Gérard Thomas, Laurent Périer-Camby. Influence of temperature on the compaction of an organic powder and the mechanical strength of tablets.. Powder Technology, 2006, 162 (2), pp.138-144. 10.1016/j.powtec.2005.12.005 . emse-00495187

\section{HAL Id: emse-00495187 \\ https://hal-emse.ccsd.cnrs.fr/emse-00495187}

Submitted on 18 Sep 2010

HAL is a multi-disciplinary open access archive for the deposit and dissemination of scientific research documents, whether they are published or not. The documents may come from teaching and research institutions in France or abroad, or from public or private research centers.
L'archive ouverte pluridisciplinaire HAL, est destinée au dépôt et à la diffusion de documents scientifiques de niveau recherche, publiés ou non, émanant des établissements d'enseignement et de recherche français ou étrangers, des laboratoires publics ou privés. 


\title{
Influence of temperature on the compaction of an organic powder and the mechanical strength of tablets
}

\author{
EMILIE ROUÈCHE(1) , ERIC SERRIS(1)* , GÉRARD THOMAS(3), LAURENT PÉRIER-CAMBY(1) \\ (1) Ecole Nationale Supérieure des Mines de Saint Etienne, Centre SPIN ; Département \\ PMCC ; LPMG -UMR CNRS 5148, 158 Cours Fauriel ; 42023 Saint-Étienne Cedex 2, \\ France
}

\begin{abstract}
The purpose of this work consists in following the dependence of physical properties on the temperature during the compaction of an organic component. A special thermo-regulated die has been developed to realize uniaxial compression at different constant temperatures. This study has shown that a temperature change modifies the microstructures and the mechanical behaviour of the tablets. The measurement of the tablet porosity during the compression cycle allows us to conclude that temperature influences mainly the phenomena occurring during the isobaric stage of the compression cycle and not the ones during the pressure increase. On the other hand, during the pressure increase, the acoustical activity of the powder is reduced when temperature increases. The tensile strength of tablets realized at different temperatures was also studied and shows a maximum around $60{ }^{\circ} \mathrm{C}$ that can be explained by the SEM analysis of the microstructure of the tablets.
\end{abstract}

Keywords:

Compression; Temperature; Organic powder; Acoustic emission; Porosity

\section{Introduction}

Granular materials are commonly used in pharmaceutical and chemical industries. In order to solve recurrent problems like powder flowability or dusty atmospheres, powders are generally compacted or agglomerated to obtain granules of larger size. More often, compaction can just be considered as a simple process to improve the packaging of material. Powders are generally stored under controlled temperature and moisture conditions but in the end they are handled in hot tablet makers, where temperature may reach $60^{\circ} \mathrm{C}$.

Classical works made on powder compaction consist in studying parameters like the maximum pressure reached, the punch velocity, and the duration of isobaric stage, on tablet properties [1], [2], [3], [4] and [5]. But the study of the influence of temperature during the compression is neglected in most cases [6], [7], [8], [9] and [10]. As a matter of fact, the behaviour of mineral compounds is not significantly modified by a temperature increase, because of their high melting point and of the low mobility of their atoms or ions at relatively low temperatures. Fragmentation, plasticity and viscosity of mineral powders are not modified by an increase of a few tens of degrees. In the opposite side, most of pharmaceutical and chemical products, in particular organic products, are sensitive to temperature and exhibit quite low melting points. Therefore plasticity and viscosity of such products can be significantly modified by a slight increase of temperature.

The aim of this work is to examine the influence of the temperature on the compressibility of an organic powder commonly used in the pharmaceutical or chemical industry. In our case,

* Auteur à qui la correspondance devait être adressée : $\underline{\text { serris@emse.fr }}$ 
the temperature and the humidity of the room are controlled and fixed at $20{ }^{\circ} \mathrm{C}$ for the temperature and $50 \%$ for humidity for all experiments, except the temperature varying from $20{ }^{\circ} \mathrm{C}$ to $120{ }^{\circ} \mathrm{C}$ in uniaxial press tests. The consequences on mechanical properties and on the structure of the tablets have been studied. In order to determine whether the powder grain may develop cracks under compaction, an apparatus has been mounted on the die to follow the acoustic emission produced by the grains during the compaction cycle. Mechanical properties have been determined by a diametral-compression test and the faces of tablets fractured after the Brazilian test were observed by SEM.

\section{Experimental procedure}

A temperature controlled die has been developed. Different studies have been carried out to characterize the evolution of the porosity, the mechanical strength and the modification of the fracture surface of tablets as function of temperature. Results are linked to the acoustic activity measured during the compression, as done in previous works with cornstarch and aspirin [11]

\section{II.1. Material and methods}

\section{II.1.1 Material}

Only one organic powder, named product A has been used for this study. It exhibits a viscoplastic behaviour and a melting point close to $150{ }^{\circ} \mathrm{C}$. This product of the chemical industry is provided as a white powder showing a narrow particle size distribution centred to a mean diameter of $300 \mu \mathrm{m}$. The true density of this powder is measured by using the helium pycnometry technique (Micromeritics, Accu Pyc 1330): the value is equal to $1.40 \mathrm{~g} \mathrm{~cm}^{-3}$. An $\mathrm{X}$-ray analysis, mentioned below, will show that this value will be considered as constant in the range of temperature studied.

\section{II.1.2 Methods}

Tablets are produced at constant mass of about $0.5 \mathrm{~g}$ in a $13 \mathrm{~mm}$ diameter die with a $5 \mathrm{kN}$ press LLOYDS. Two series of tablets are made to allow analyses just after the ejection for a first group and $24 \mathrm{~h}$ after the ejection for the other tablets. Final tablets are $2 \mathrm{~mm}$ in height.

Six cylindrical holes are regularly placed in the die around the centre hole dedicated to the powder and the punches. Six heating rods (Figure 1) equipped with thermocouples $J$ are inserted in the holes and connected to a temperature regulator TGC 2000 from Setaram. The rods are resistors, which each can deliver a power of $250 \mathrm{~W}$. The maximum power delivered by the regulator is $2000 \mathrm{~W}$ under $220 \mathrm{~V}$. The temperature regulator was calibrated before use. One rod was placed in a bath regulated in temperature and the values measured by the thermocouple were plotted versus the real temperature of the bath. A linear equation was found: $T_{\mathrm{R}}\left({ }^{\circ} \mathrm{C}\right)=5.265 T_{\mathrm{B}}\left({ }^{\circ} \mathrm{C}\right)-120.08$, where $T_{\mathrm{R}}$ is the temperature measured by the thermocouple of the rod and $T_{\mathrm{B}}$ is the temperature of the bath. The LMS error, $R^{2}$, is equal to 1. Once submitted to a temperature increase, the die takes quite a long time to get stabilized. For example, to heat the die and reach a constant temperature of $50{ }^{\circ} \mathrm{C}, 1 \mathrm{~h}$ is needed. So a preheating time of $3 \mathrm{~h}$ has been imposed before the insertion of the powder.

Now let us consider the protocol chosen for the compaction experiments.

The die is first cleaned with alcohol and pre-lubricated with a solution of magnesium stearate $\left(5 \mathrm{~g} \mathrm{~L}^{-1}\right)$ before being heated. After a $3 \mathrm{~h}$ heating, the powder is inserted inside the die. Then a period of $15 \mathrm{~min}$ is imposed before beginning the experiments. In this way the homogeneity in temperature in the powder is ensured. Two piezoelectric sensors are fixed around the die to measure the acoustic activity of the powder during the compression: see later on how the acoustical emissions are measured. The compression cycle can be shown in Figure 2. In a first time, pressure increases at a punch velocity $V_{\mathrm{m}}=10 \mathrm{~mm} \mathrm{~min}^{-1}$ up to a maximum pressure $P_{\max }=50 \mathrm{MPa}$. Then the pressure remains constant during a dwelling time $t_{\mathrm{p}}=30 \mathrm{~min}$, and finally the pressure decreases with a corresponding constant punch velocity of $V_{\mathrm{d}}=10 \mathrm{~mm}$ $\min ^{-1}$. The punch stops only when it reaches its initial position. The time $t_{\mathrm{d}}$, which represents the duration between the end of the experiment and the ejection of the tablet, is nil. The time $t_{\mathrm{r}}$ before characterization is nil or equal to $24 \mathrm{~h}$ in function of the group of tablets realized. All 
the parameters of the compression cycle are summed up in Table 1. The temperature is kept constant during all the experiments between 20 and $140^{\circ} \mathrm{C}$.

\section{II.2. Analyses}

In order to understand the influence of the pressure on the porosity and on the mechanical strength of the tablets, several characterizations have been carried out. First of all, thanks to the transducer placed on the head of the punch, one can follow the porosity under stress during the pressure increase $n(P)$ and during the isobaric stage $n\left(t_{\mathrm{p}}\right)$. In the same time, measurements of the number of events of acoustical emission are realized. After ejection and a relaxation time of $24 \mathrm{~h}$, the mechanical strength $R(T)$ of tablets prepared at different temperatures are also measured. The faces of the fractured tablet are analysed by SEM to observe the evolution of the internal structure with the temperature. Finally the XRD analysis gives us information on the evolution of the degree of crystallinity of the material as a function of the temperature

\section{II.2.1. Study of the porosity}

Two gauges measure the displacement and the force applied by the punch on the powder during the compression cycle. The initial position of the punch is collected for each experiment to bring a correction on the displacement of the punch: this series of data makes possible to compare all the experiments. These values are recorded by the software controlling the press and one can calculate the evolution of the porosity of the powder as a function of pressure and time. The porosity under pressure ( $n$ ) can be defined by Equation (1).

$n=\frac{V_{p}}{V_{a p p}}=\frac{V_{a p p}-V_{s}}{V_{a p p}}=1-\frac{m_{s}}{\pi \times r^{2} \times \rho_{s} \times \Delta l}$

$V_{\mathrm{p}}$ : the porous volume, $V_{\mathrm{app}}$ : the total volume (pores + grains), $V_{\mathrm{s}}$ : the solid volume, $m_{\mathrm{s}}$ : the weight of powder, $r$ : the internal radius of the die (radius of tablets), $\rho_{\mathrm{s}}$ : the density of the powder, $\Delta l$ : the height of powder in the die.

To get precise values of the porosity, we should know the variations of the density of a product with the temperature, but it is not the case for the product studied. Nevertheless, by considering that such variations present only second order effects, significant conclusions can be deduced anyway. All the curves shown in this paper are built as the average values from 4 experiments.

\section{II.2.2. Study of the acoustic emissions}

As indicated in Figure 2, several phenomena [12], [13] and [14] appear during the compression cycle: granular rearrangements, fragmentation, and elastic, viscous, or plastic deformations of the media. A phenomenon like fragmentation emits numerous acoustic waves. The frequency domain concerned by these acoustic emissions (A.E.) is wide from 10 to $120 \mathrm{kHz}$. Once detected and registered, the acoustic signals are analysed to determine which phenomenon occurs during the compression cycle and its characteristics.

To record A.E., two piezoelectric sensors are placed at two opposite positions around the die at the powder level (Figure 1 and Figure 3). A compression cycle is realized without powder to measure the "blank" that will be considered as the background noise and removed from all values.

The software "Mistras", developed by Euro Physical Acoustics, allows the acoustic signals to be acquired and treated. It allows the visualization and the analysis in real time of the acoustic bursts (amplitude, energy, duration, number of counts). A count represents one acoustic event, whereas a burst is the sum of several events that together represent a real event (a fragmentation for example). To be taken into account in a burst, counts must present amplitude higher than the amplitude of the background (measured during a compression experiment without powder in the die). In our case, the value of the background is $40 \mathrm{~dB}$. 


\section{II.2.3. Tablet strength}

A diametral-compression test is realized with a durometer Vanderkamp in order to estimate the mechanical strength of tablets. This test consists in compressing tablets diametrically between two platens with a force increasing up to a maximum $F$ for which the tablet is fractured. The determination of the tensile strength is possible thanks to the relation of Fell and Newton [15] (Equation (2)). Tablets are considered as cylinders of diameter $D$ and height $e$. So the value for the maximum tensile stress, $R$, is constant over the whole of the load diameter and presents a magnitude:

$R=\frac{2 F}{\pi \times D \times e}$

\section{Results and discussion}

\section{III.1. Effects of the compression cycle parameters}

At the beginning of the pressure increase, grains reorganise themselves without noticeable deformation (simple packing). Indeed, the initial volume of powder is quite aerated, so that grains can easily move under the local shear and axial stress to reach a higher compacted state (blocked state). This state is characterized by an important number of contacts per grain. When this state is reached and the pressure continues to increase, grains are deformed (elastically or viscously) and/or are fractured. The plastic irreversible deformations appear instantaneously during the pressure increase. During the isobaric stage, the viscous deformations of the granular medium submitted to a constant axial stress are also irreversible but appear as a time-dependent phenomenon. These deformations of the grains provoke more and more important rearrangements of the granular medium, with variations of the mean locations and the shape of the grains, especially around each contact. These deformations lead to a better cohesion between grains. The packing fraction still increases. During the decrease of pressure, elasticity effects may appear in tablets, sometimes leading to a loss of cohesion of the tablets and defects (layering, capping). This is not the case for product A.

At the end of the compression cycle, before or after the tablet ejection, the reorganisation of the compact continues. The global volume of tablets generally increases. This phenomenon is also considered as a viscous relaxation of the shear stresses.

\section{III.1.1. Evolution of the porosity during the pressure increase}

The temperature at which the compression is realized has a noticeable influence on the compression of the product A (Figure 4). At temperature less than $100{ }^{\circ} \mathrm{C}$, the curves are similar. That allows us to conclude that the temperature presents no marked influence during the pressure increase for temperatures less than $100{ }^{\circ} \mathrm{C}$. The types of reorganisation must be similar and remain unchanged in this temperature range. On the opposite side, the shape of the curves is completely changed for temperatures higher than $100{ }^{\circ} \mathrm{C}$. The explanation probably lies in different types of reorganisation.

\section{III.1.2. Evolution of the porosity during the isobaric stage}

The influence of the temperature on the evolution of the porosity during the isobaric stage is important (Figure 5). Up to $80{ }^{\circ} \mathrm{C}$, the porosity decreases while the temperature increases. But for temperature higher than $80^{\circ} \mathrm{C}$, the shape of the curves is completely modified: the temperature close to the melting point of the powder induces significant modifications on the powder behaviour. In order to calculate the points and plot curves, Equation (1) was applied with the measured true density of the pure product $\left(1.40 \mathrm{~g} \mathrm{~cm}^{-3}\right)$. But near the melting point, the product may begin to become very ductile and locally even starts melting in some regions so that its density may change as well. As a consequence, the porosity calculated using Eq. (1) for temperature higher than $100{ }^{\circ} \mathrm{C}$ might present higher uncertainties. From a more general point of view, powder density measurements seem to be quite essential prerequisites for available assessments for data of this kind, under temperature thermodynamically compatible with the solid form. In this case, the problem of the phase transition is superimposed. 


\section{III.2. Influence of temperature on the A.E.}

In this part, two types of graphs have been superimposed: pressure versus time and the cumulative number of counts versus time. Data have been obtained thanks to the two piezoelectric sensors placed around the die. The curves obtained are presented in Figure 6 for two different temperatures.

One can notice an increase of the acoustic activity when the temperature increases. This observation might be linked to an increase of the number of grain fractures.

\section{III.3. Influence of temperature on the mechanical strength}

Figure 7 shows a great influence of the temperature on the tablet tensile strength. Whatever the relaxation time after the ejection is, the tensile strength is maximum around $60^{\circ} \mathrm{C}$.

Between 20 and $80{ }^{\circ} \mathrm{C}$, the evolution of the porosity under pressure (Figure 4) does not depend on the temperature in contrast with the evolution of the mechanical strength that increases with the temperature (Figure 7). The A.E., strongly connected to the rate of fragmentation, also increases with the temperature (Figure 6). In fact, the growing number of fragmentations creates new areas of contact between grains, which improve the mechanical strength. The study of the relaxation time shows only a small influence on the curve $R(T)$. Whatever the temperature is, the tensile strength needed to break a tablet is increased by the relaxation time.

\section{III.4. Evolution of tablet cohesion}

The internal microstructures of fractured tablets have been observed and analysed by SEM. The grains of product A are clearly evidenced on the picture taken from tablets made at room temperature (Figure 8a). A typical inter-granular fracture can be observed. A zoom $(\times 10)$ focused on the interface between two grains shows that the pores still remain between particles of mean size $10 \mu \mathrm{m}$ ( Figure $8 \mathrm{~b}$ ).

For tablets made at $60{ }^{\circ} \mathrm{C}$, the grains seem to be more difficult to identify (Figure 9a). A transgranular type fracture has occurred inside the grains, sharing crystalline planes. This observation is confirmed in Figure $9 \mathrm{~b}$ where stripes can be seen. The temperature increase has favoured grain cohesion and therefore fractures occur inside the grains and not between the grains. This could explain the increase of the tablet tensile strength.

For tablets made at $140{ }^{\circ} \mathrm{C}$, grains are no more evidenced, but a continuum of matter takes place (Figure 10a). There is no free space between grains and the porosity is considerably lowered. The facets in Figure 1ob confirmed the type of trans-granular fracture observed. The tablets behave like a continuum of matter: from this point of view, the mechanical strength would increase at first sight, but during the cooling (and after ejection of the tablet); cracks may appear and propagate inside the relaxed tablets. As a consequence, tablets might become brittle and the mechanical strength decreases. Cracks are visible in Figure 1ob.

\section{III.5. Evolution of the structure}

Diffractograms of tablets made at room temperature and at $140{ }^{\circ} \mathrm{C}$ are similar after cooling. The diffraction lines are identical showing that no chemical transformation has happened; but their intensities are somewhat different. In situ XRD analysis directly on the powder have also been carried in a high temperature camera showing the same kind of results under heating or cooling. A variation can also be noticed in the intensity of the peaks (orientation effect). The variations observed on the peak positions are very small when temperature increases: the lines slightly move either to the left or the right depending on the Miller indexes, but these displacements are not important enough to conclude to the creation of a new crystal lattice. The only phenomenon explaining these observations would be a very small dilatation of the elementary cell of the crystallites when the temperature increases. A refinement of the elementary cell parameters developed by a least square method for diffractograms obtained at different temperatures do not show great changes in the values of the elementary cell (elementary cell volume variation $<10^{-3}$ ).

The hypothesis that the true powder density does not vary with temperature is therefore verified. The maximum in the mechanical strength cannot be explained by this small and 
monotonous modification of the lattice. Obviously changes in the mechanical strength on heating are not linked to the density variation.

\section{Conclusions}

The compression of an organic powder has been studied under various conditions of pressure and temperature. XRD analysis has shown that this powder does not present any structure modification as observed in thermal decompositions or polymorphic transformations. The true density remains constant in the temperature range studied.

Tablets have been elaborated in an original heating compression die. Phenomena occurring are followed using continuous monitoring of acoustic emission and porosity variations under stress. Discrete characterizations of the mechanical strength and of the fracture surface morphology have been performed.

It was observed that the rate of isobaric compaction is considerably enhanced above $100{ }^{\circ} \mathrm{C}$, which could be attributed to the vicinity of the melting point. Moreover the evolution of porosity versus time during the isobaric stage depends strongly on temperature. These evolutions are in connection with the visco-plastic behaviour of the product at the scale of few minutes.

The mechanical strength exhibits a maximum near $60{ }^{\circ} \mathrm{C}$ : microstructure studies show that inter-granular cracks appear and propagate into the tablets prepared above this temperature during cooling. The higher the temperature the greater the number of defects in the tablets is, as seen in SEM experiments. On the one hand raising the temperature allows a gain in plasticity and then in cohesion and hardness. On the other hand, for temperature close to the melting point, at the ejection from the die, a hard cooling creates cracks in tablets and a decrease of the mechanical strength occurs.

In the same way, acoustic emission is enhanced by a rise in temperature, due to an increase in the number of grain fractures under loading conditions.

This study shows that an optimum temperature exists to get a better cohesion in tablets of organic materials. For the product A, $60{ }^{\circ} \mathrm{C}$ seems to be the good choice of temperature to enhance good mechanical strengths. This can be a good example to guide optimisation of compaction processes for organic powders, deeply depending on temperature.

\section{References}

[1] R.W. Heckel, Density-pressure relationship in powder compaction, Trans. Metall. Soc. AIME 221 (1968), pp. 671-675.

[2] P. Humbert-Droz, D. Mordier and E. Doelker, Méthode rapide de détermination du comportement à la compression pour les études de préformulations, Pharm. Acta Helv. 57 (1982) (5-6), pp. 136-143.

[3] M. Cetik, Overview of compaction data analysis technique, Drug Dev. Ind. Pharm. 18 (1992) (6-7), pp. 767-810.

[4] W.C. Duncan-Hewitt and G.C. Weatherly, Modeling the uniaxial compaction of pharmaceutical powders using the mechanical properties of single crystals: I. Ductile materials, J. Pharm. Sci. 79 (1990) (2), pp. 147-152.

[5] C. Thornton and S.J. Antony, Quasi-static deformation of a soft particle system, Powder Technol. 109 (2000), pp. 179-191.

[6] J.C. Masteau and G. Thomas, Evolution and modelling of compacted binary mixture porosity. Application to pharmaceutical tablets, J. Chim. Phys. 96 (1999), pp. 12451268.

[7] T. Higuchi, L.N. Elowe and L.W. Busse, The physics of tablet compression: V. Studies on aspirin, lactose, lactose-aspirin, and sulfadiazine tablets, J. Am. Pharm. Assoc. 18 (1954) (11), pp. 685-689.

[8] P. Paronen and M. Juslin, Compressional characteristics of four starches, J. Pharm. Pharmacol. 35 (1983), pp. 627-635.

[9] C. Gustafsson, C. Nyström, H. Lennholm, M.C. Boneferoni and C. Caramella, Characteristics of hydroxypropyl methylcellulose influencing compactability and 
prediction of particle and tablet properties by infrared spectroscopy, J. Pharm. Sci. 92 (2003), pp. 494-504.

[10] O. Saint-Raymond, Study of the influence of the texture and structure of pharmaceutical products on their compressibility, Thesis Ecole Nationale Supérieure des Mines de Saint-Etienne, France (1995).

[11] M.J. Waring, M.H. Rubenstein and J.R. Howard, Acoustic emission of pharmaceutical materials during compression, Int. J. Pharm. 36 (1987), pp. 26-29.

[12] E. Serris, L. Perier-Camby, G. Thomas, M. Desfontaines and G. Fantozzi, Acoustic emission of pharmaceutical powders during compaction, Powder Technol. 128 (2002), pp. 296-299.

[13] A.A. Pollock, History of acoustic emission, Non-Destr. Test. Handb. 3 (1975) (8), pp. $593-597$.

[14] E. Serris, Influence of the compression conditions on the physical and chemical properties of organic tablets, Thesis Ecole Nationale Supérieure des Mines de SaintEtienne, France (2002).

[15] J.T. Fell and J.M. Newton, Determination of tablet strength by the diametralcompression test, J. Pharm. Sci. 59 (1970) (5), pp. 688-691.

\section{Figures}

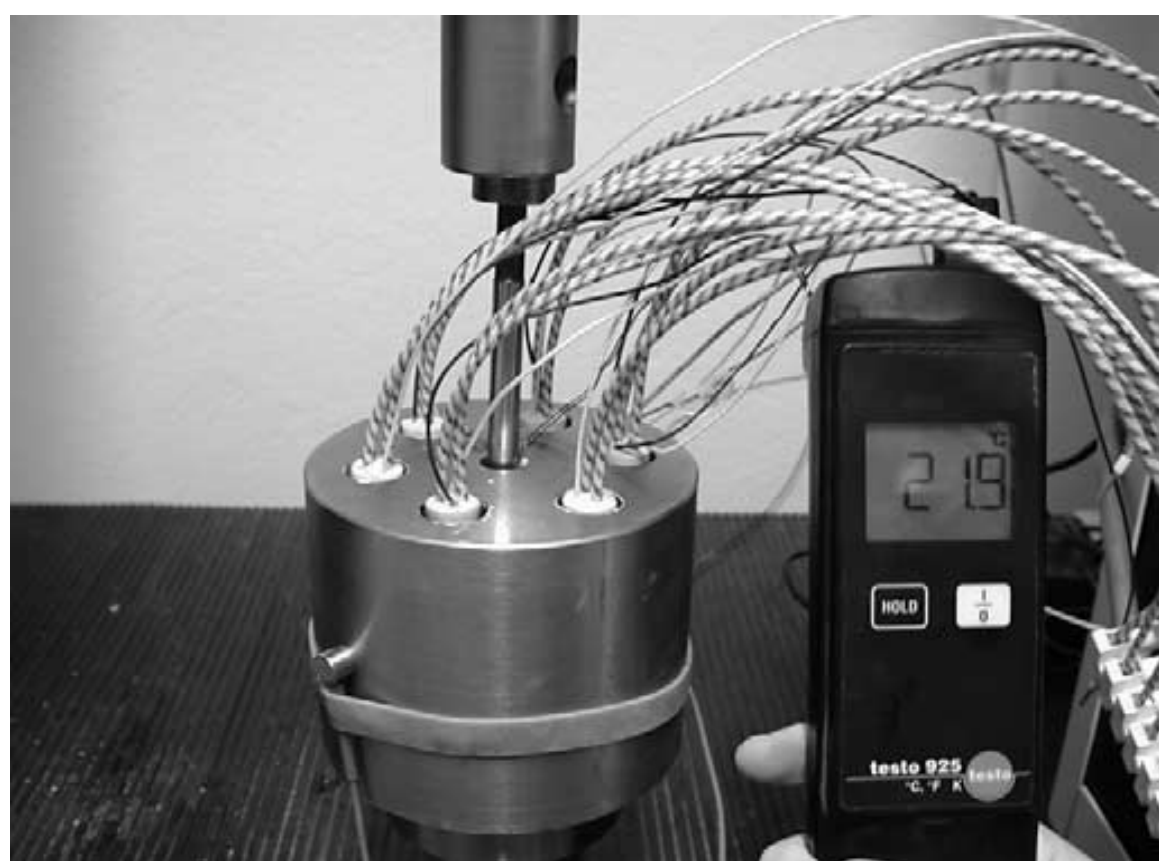

Figure 1: The uniaxial die with the 6 heating rods with a temperature regulation system. The piezoelectric sensor used to detect the acoustic emissions can be seen on the left.

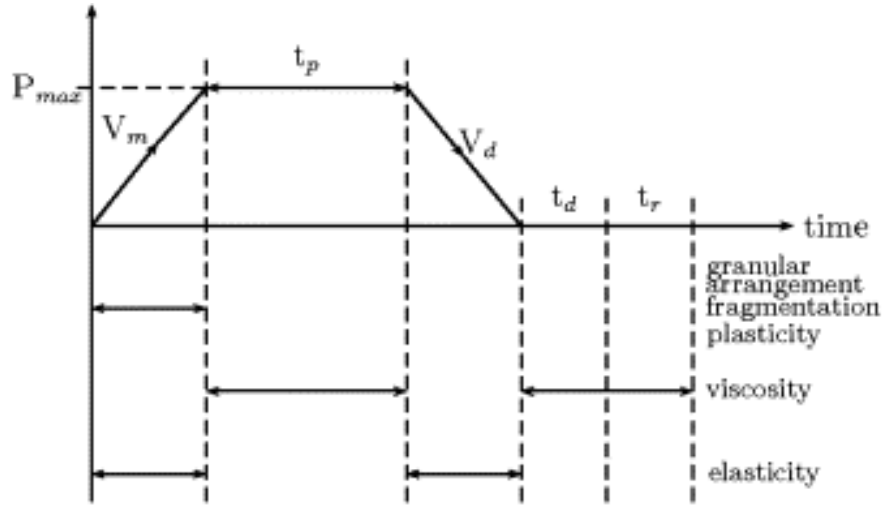

Figure 2: Compression cycle. 


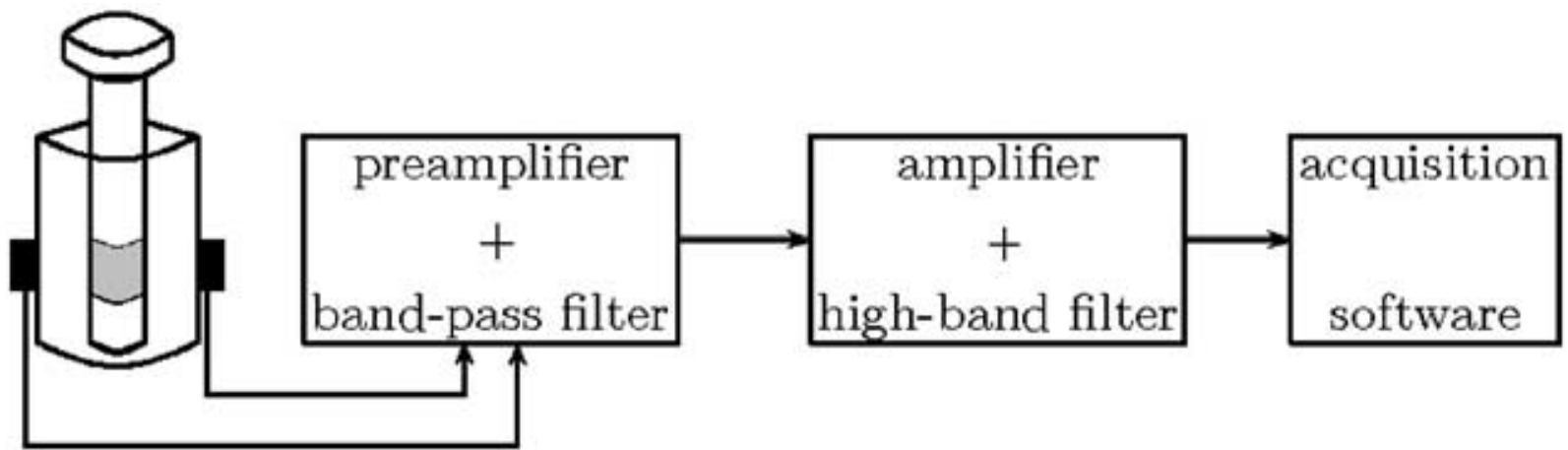

Figure 3: Acquisition of data for characterizing acoustic emissions.

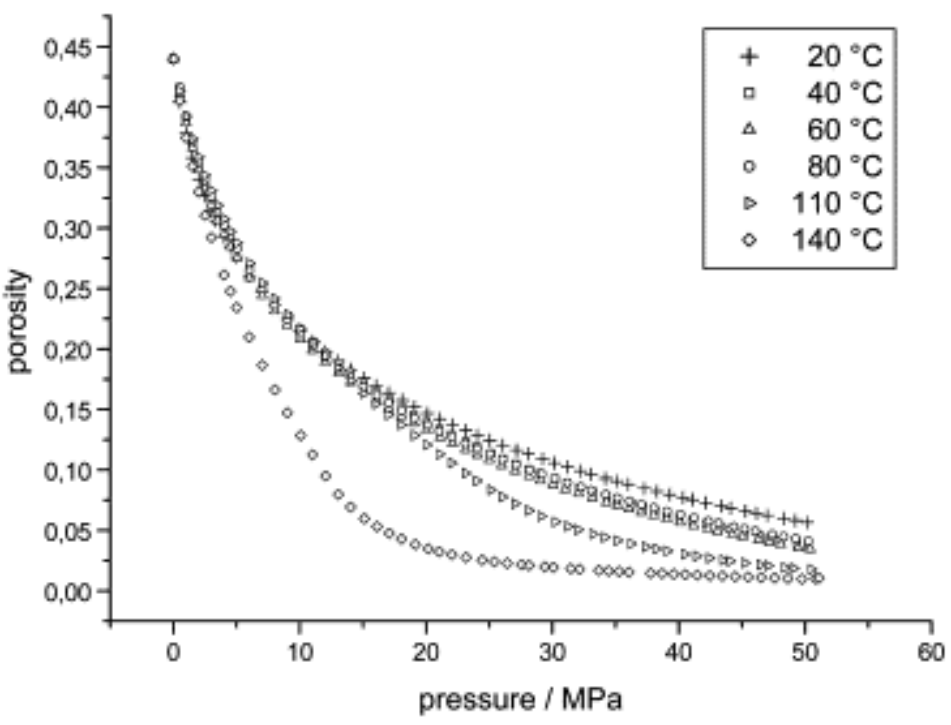

Figure 4: Evolution of the porosity of the product A during the pressure increase for different temperatures.

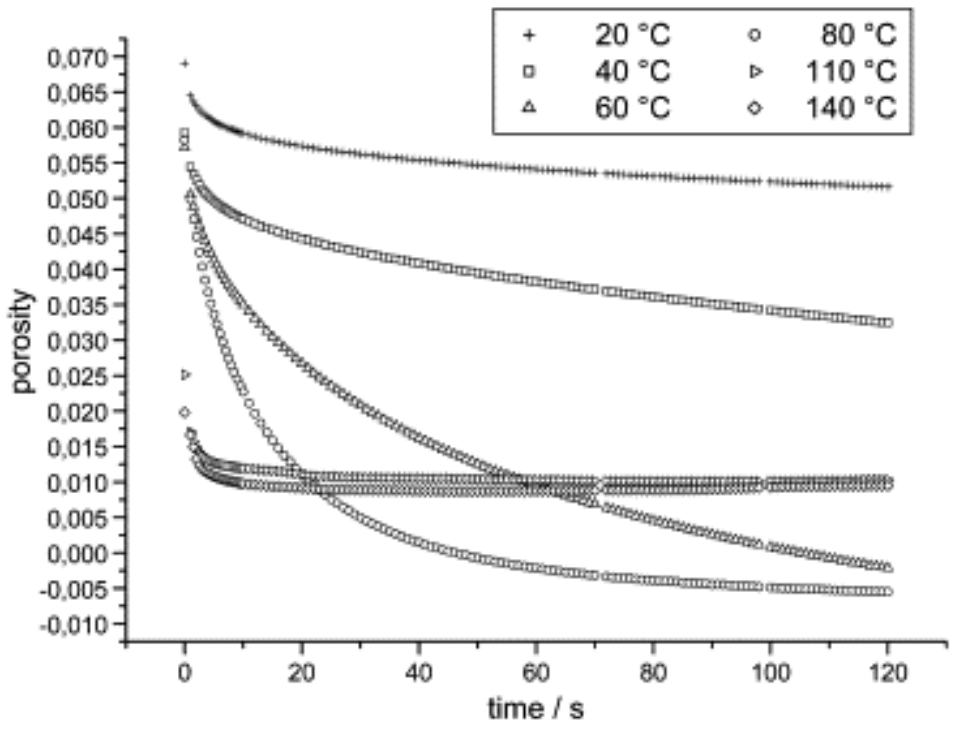

Figure 5: Evolution of the porosity of the product A during the isobaric stage for different temperatures. 

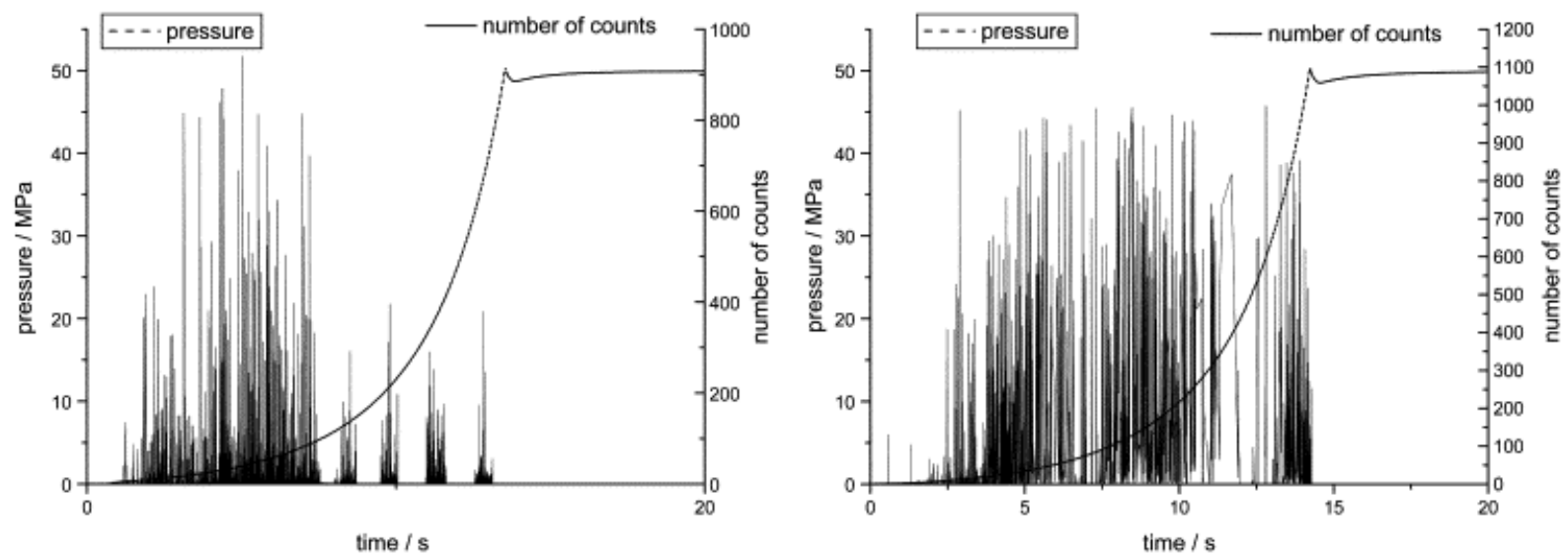

Figure 6: Pressure and A.E. versus time at $25^{\circ} \mathrm{C}$ (left) and at $40^{\circ} \mathrm{C}$ (right).
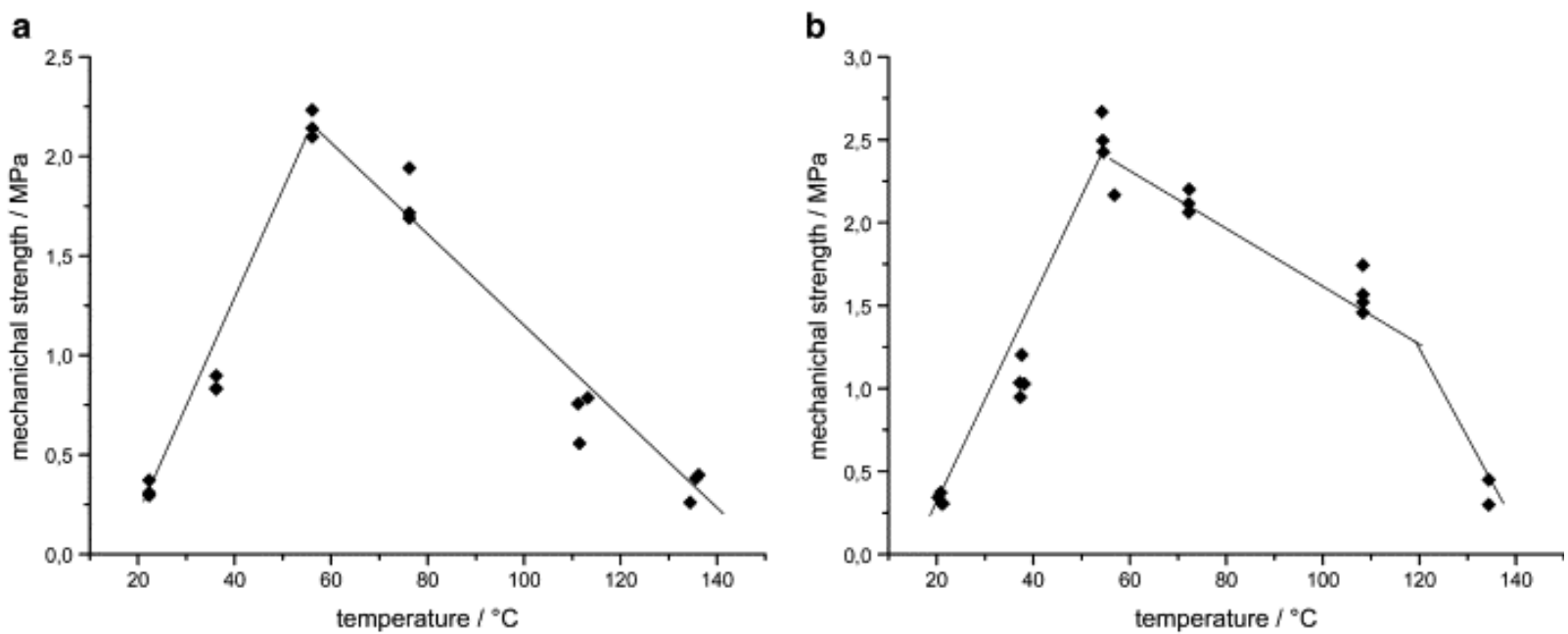

Figure 7: Results of mechanical strength obtained by diametral-compression tests (a) after the ejection of tablets $\left(t_{d}=o\right)$ and after $(b)$ a relaxation time $\left(t_{r}=24 \mathrm{~h}\right)$.
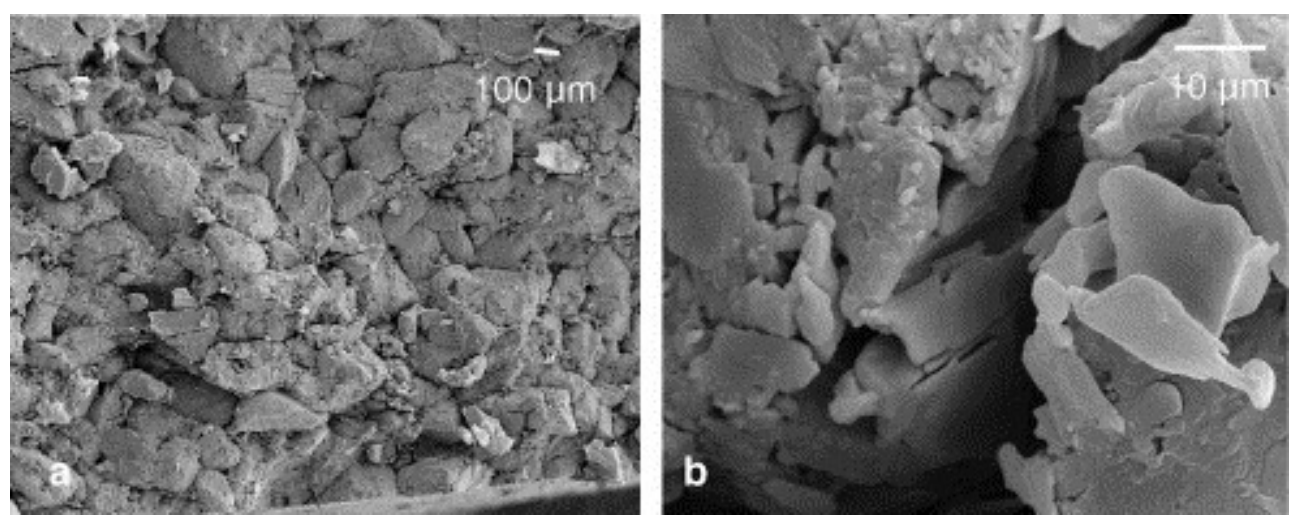

Figure 8: Fractured face of a tablet made at room temperature. 

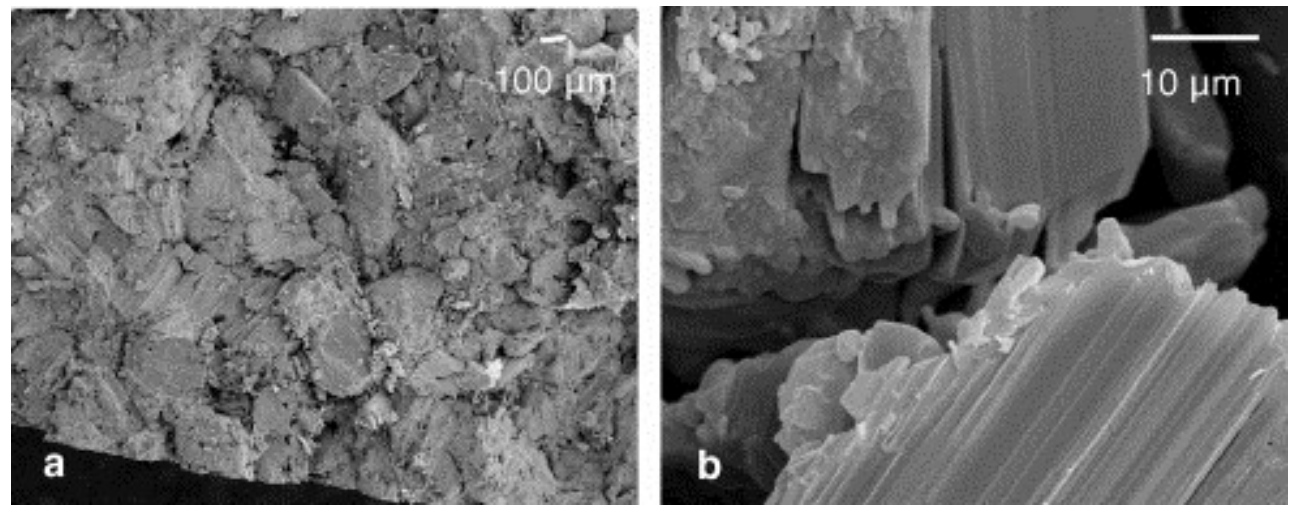

Figure 9: Fractured face of a tablet made at $60^{\circ} \mathrm{C}$.
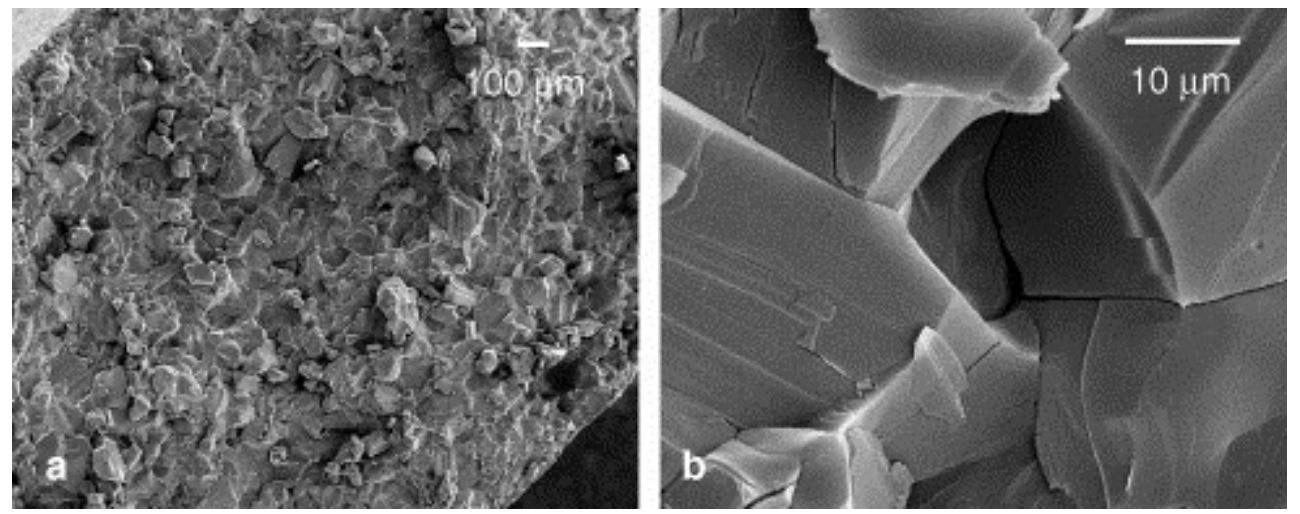

Figure 10: Fractured face of a tablet made at $140{ }^{\circ} \mathrm{C}$ after cooling at room temperature.

\section{Tables}

Table 1: Experimental protocol

\begin{tabular}{|l|l|l|l|l|l|l|}
\hline Temperature $\left({ }^{\circ} \mathrm{C}\right)$ & $V_{m}$ & $P_{\max }$ & $t_{p}$ & $V_{d}$ & $T_{d}$ & $T_{r}$ \\
\hline 25,60 and 140 & $10 \mathrm{~mm} \mathrm{~min}^{-1}$ & $50 \mathrm{MPa}$ & $30 \mathrm{~min}$ & $10 \mathrm{~mm} \mathrm{~min}^{-1}$ & o min & o min or $24 \mathrm{~h}$ \\
\hline
\end{tabular}

$\mathrm{V}_{m}$ and $\mathrm{P}_{\max }$ are chosen in agreement with general industrial application requirement. The dwell time $\mathrm{t}_{p}$ is extended to 30 min as to evidence porosity variation versus time, but porosity variation cannot be observed during the very short dwell time during industrial application (see Figure 5 to evaluate the time scales for the viscous behaviour of the material). The time $\mathrm{t}_{d}$ is nil, as in industrial applications, but one can sometimes identify effects of this parameter in some experiments, like "push out experiments" allowing to follow the strength necessary to extract the tablet. $\mathrm{t}_{\mathrm{r}}$ can take two values: $\mathrm{o}$ min or $24 \mathrm{~h}$ (porosity of relaxed tablets). 